\title{
A MEDIAÇÃo COMUNITÁRIA A PARTIR dO CONVÊNIO COM O TRIBUNAL DE JUSTIÇA DO RIO DE JANEIRO
}

\author{
THE COMMUNITY MEDIATION FROM THE COVENANT WITH THE RIO DE \\ JANEIRO COURT OF JUSTICE
}

\section{FERNANDA BRAGANÇA 1 LAURINDA FÁTIMA BRAGANÇA²}

RESUMO: Esta pesquisa é inserida na proposta do Laboratório Fluminense de Estudos Processuais LAFEP de investigação da mediação em uma perspectiva multidisciplinar. $O$ artigo trata da implantação da mediação comunitária na cidade do Rio de Janeiro a partir do convênio firmado entre o Tribunal de Justiça, a Prefeitura e a Arquidiocese Metropolitana. O trabalho visa a contribuir com a apresentação das perspectivas teórica e prática do procedimento bem como sinaliza alguns desafios que ainda precisam ser superados.

PALAVRAS CHAVES: Mediação comunitária. Empoderamento. Cidadania. Participação democrática. Cultura de paz.

ABSTRACT: This research is inserted in the proposal of Fluminense Laboratory of Procedural Studies - LAFEP to investigate mediation in a multidisciplinary perspective. The article deals with the implementation of community mediation in the city of Rio de Janeiro, based on an agreement signed between the Court of Justice, the City Hall and the Metropolitan Archdiocese. The work aims to contribute to the presentation of the theoretical and practical perspectives of the procedure as well as signals some challenges that still need to be overcome.

KEYWORDS: Community mediation. Empowerment. Citizenship. Democratic participation. Culture of peace.

\footnotetext{
1 Doutoranda no Programa de Sociologia e Direito da Universidade Federal Fluminense - UFF. Mestre em Direito pela Universidade Federal do Rio de Janeiro - UFRJ/FND. Graduada em Direito pela Universidade Federal do Rio de Janeiro - UFRJ/FND. Graduada em Administração de Empresas pela Universidade Cândido Mendes /UCAM. Pesquisadora do Laboratório Fluminense de Estudos Processuais - LAFEP. Advogada. Mediadora Extrajudicial. Mediadora Comunitária

2 Doutora pela Pontifícia Universidade Católica do Rio de Janeiro - PUC-Rio. Mestre pela Coppe/UFRJ. Professora da Universidade Federal Fluminense - UFF.
} 


\section{INTRODUÇÃO}

Este estudo está inserido na proposta de pesquisa do Laboratório Fluminense de Estudos Processuais - LAFEP da Universidade Federal Fluminense - UFF, que tem como um dos seus pontos de investigação a análise da mediação em uma perspectiva multidisciplinar. Essa investigação tem como objetivo relatar a origem da mediação comunitária no estado do Rio de janeiro a partir do convênio firmado entre o Tribunal de Justiça (TJRJ), a prefeitura da cidade do Rio e a Arquidiocese Metropolitana, e também apontar como o trabalho nos centros vem se desenvolvendo até então.

$\mathrm{O}$ artigo conta com a seguinte metodologia: a primeira etapa consistiu em uma pesquisa bibliográfica sobre os fundamentos teóricos da mediação comunitária: conceito, princípios, objeto, pessoas que podem procurar o serviço, mediadores, procedimentos e principais vantagens. Esse tipo de análise persistiu sobre duas repercussões importantes: o empoderamento, que propõe o resgate da autonomia do indivíduo em gerir e solucionar seus conflitos. Dessa maneira, ao invés de passar toda e qualquer questão à apreciação judicial, os envolvidos buscam por si mesmos, a partir da real compreensão de seus interesses e necessidades, alcançar um equacionamento de suas contendas. E a promoção da cidadania, que envolve a valorização do exercício dos direitos e a reconquista de valores como o respeito, tolerância, solidariedade e participação democrática.

No momento seguinte, passa-se então a relatar a experiência prática enquanto mediadora comunitária em capacitação pelo Tribunal trazendo os aprendizados da formação e os principais pontos discutidos durante as reuniões com o núcleo permanente de métodos consensuais de solução de conflitos - o NUPEMEC, responsável pelos centros instalados nos espaços cedidos pela municipalidade e pelas paróquias. O objetivo é colaborar com a percepção do cenário em que a mediação comunitária vem sendo implantada no rio de janeiro e as dificuldades que até então vem sendo encontradas. Destaca-se sobretudo nessa oportunidade a baixa procura pelos serviços dos centros, a exceção dos localizados nas comunidades da Coroa e da Rocinha, o que evidencia que a cultura da litigância é marcante e vai exigir esforços mais intensos para ser transformada. Esta é uma pesquisa em andamento e 


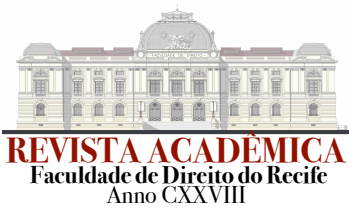

que seguirá acompanhando as evoluções e coletando os principais dados da implantação desse serviço.

\section{A MEDIAÇÃo COMUNITÁRIA}

A Mediação comunitária é um procedimento extrajudicial realizado em espaços externos ao ambiente Judiciário, independentemente da condição sócio-econômica dos interessados, com dois objetivos principais: um primário, que é fazer com que as partes retomem o diálogo para conviver de maneira pacífica e harmoniosa; e um secundário, que é o desfecho com o acordo. Ainda que a doutrina especializada não apresente um conceito fechado $^{3}$, alguns aspectos são comumente abordados pelos estudiosos do assunto: ela tem dois eixos fundamentais, um voltado ao atendimento, que dá orientação relativa ao exercício da cidadania e de direitos humanos e que se ocupa de conflitos no âmbito privado das relações interpessoais; e um segundo, que está relacionado às questões coletivas, como a organização da sociedade e a coletivização de demandas (ALMEIDA; PANTOJA, 2016, p. 126).

Funciona como um serviço público prestado pelos membros da própria comunidade, tendo em vista que os mediadores ${ }^{4}$, ou seja, os terceiros responsáveis por conduzir o procedimento, são pessoas inseridas na localidade e que portanto, conhecem e compartilham da mesma realidade.

\footnotetext{
3 Alguns autores, como por exemplo a autora Sally Merry (1996), utilizam o termo comunidade como equivalente a grupo de pessoas de baixa renda. Com esse viés, a mediação comunitária seria um instrumento de empoderamento de indivíduos considerados carentes.

4 O mediador é um gestor de conflitos, um facilitador que deverá ser sempre imparcial, não devendo impor soluções. Quem decide são os interessados. A sua principal função é ajudá-los a decidir por suas próprias convicções.

São 3 os pilares da mediação: o mediador, os mediandos e as atividades de mediação. A essência da mediação é a própria atividade do mediador. O novo Código de Processo Civil conceitua:

Art. 165. § 3o O mediador, que atuará preferencialmente nos casos em que houver vínculo anterior entre as partes, auxiliará aos interessados a compreender as questões e os interesses em conflito, de modo que eles possam, pelo restabelecimento da comunicação, identificar, por si próprios, soluções consensuais que gerem benefícios mútuos.
} 


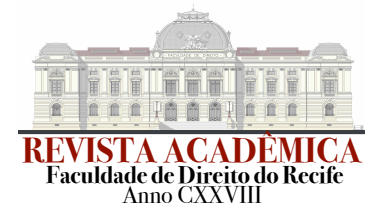

Os princípios que regem a mediação comunitária são basicamente idênticos aos da mediação em geral 5 , com algumas especificidades. O Código de ética do mediador comunitário trata-os em seu art. 306: autonomia das partes, imparcialidade, credibilidade, competência, confidencialidade, diligência e livre escolha do mediador comunitário. Já no que toca aos valores que a norteiam a mediação temos fundamentalmente: o crescimento pessoal; a transformação social; e a prestação de auxílio na resolução de conflitos (OLIVERA, 2005, p. 33). O desenvolvimento de cada indivíduo contribui também para que a comunidade se legitime e se fortaleça, de maneira que ganha força ao exigir o atendimento de suas necessidades frente tanto Poder Público quanto à iniciativa privada.

Uma das maiores vantagens da opção por essa via de solução de conflitos é a prevenção da violência, tendo em vista que a controvérsia tende a ser resolvida pelos envolvidos e não por alguém que desconhece o ambiente no qual estão inseridos. Não há perdedores pois todos precisam ter uma postura ativa de propor e aquiescer com o que está sendo acordado. Outra tendência é que tudo seja equacionado de forma muito mais célere.

O seu objeto são aquelas questões que atingem a localidade na qual o centro encontrase inserido, como por exemplo: problemas de bairro ou entre bairros, vizinhança, segurança

5 O art. 2o da Lei 13. 140/2015, que dispõe sobre a mediação entre particulares como meio de solução de controvérsias e sobre autocomposição de conflitos no âmbito da administração pública, estabelece que a mediação será orientada pelos seguintes princípios: I. Imparcialidade do mediador; II. Isonomia entre as partes; III. Oralidade; IV. Informalidade; V. Autonomia da vontade das partes; VI. Busca do consenso; VII. Boa-fé.

6 AUTONOMIA DAS PARTES: $§ 1^{\circ}$ A mediação é um procedimento voluntário e as responsabilidades das decisões tomadas no decurso do procedimento cabem as pessoas envolvidas no conflito, devendo o mediador comunitário assegurar a plena autonomia de vontade dos interessados não fazendo prevalecer soluções, não decidindo, não defendendo e não aconselhando.

INDEPENDÊNCIA: $\S 2^{\circ} \mathrm{O}$ mediador comunitário tem o dever de salvaguardar, sob todas as formas a independência inerente a sua atividade isentando-se de qualquer pressão, seja esta resultante de seus próprios interesses, valores pessoais ou de influências externas.

IMPARCIALIDADE: $\S 3^{\circ} \mathrm{O}$ mediador comunitário é um terceiro imparcial em relação aos interessados e ao conflito em questão, devendo abster-se de qualquer ação ou comportamento que manifeste qualquer tipo de preferência (partidária, religiosa, econômica, sexual, etc.).

CREDIBILIDADE: $\S 4^{\circ} \mathrm{O}$ mediador comunitário deverá desempenhar sua atividade de forma confiável, sendo independente, franco, coerente e competente.

COMPETÊNCIA: $\S 5^{\circ} \mathrm{O}$ mediador comunitário deve ter a capacidade para mediar o conflito existente entre os interessados, satisfazendo as expectativas razoáveis dos mesmos, procurando a permanente atualização dos seus conhecimentos científicos e da sua preparação técnica e prática.

CONFIDENCIALIDADE: $\S 6^{\circ} \mathrm{O}$ mediador comunitário deve manter sigilo de todas as informações que tenha conhecimento no âmbito do procedimento da mediação comunitária, delas não podendo fazer uso em proveito próprio ou de outrem.

DILIGÊNCIA: $\S 7^{\circ} \mathrm{O}$ mediador comunitário deve ser diligente, efetuando o seu trabalho de forma prudente e eficaz, assegurando a qualidade do processo e cuidando ativamente de todos os seus princípios fundamentais.

LIVRE ESCOLHA DO MEDIDADOR: $\S 8^{\circ}$ Aos interessados assiste o direito à livre escolha do mediador comunitário disponível nos plantões Centos de Mediação Comunitária. 


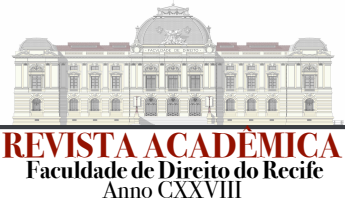

na região, problemas de consumidores em estabelecimentos locais, situações familiares, empresariais etc. A depender da especificidade da disputa, é preciso que o mediador chame a colaborar os representantes locais como: o presidente da associação de moradores, os síndicos dos condomínios, o responsável pelos lojistas, dentre outros.

Qualquer pessoa, independentemente de sua condição econômico-financeira, pode procurar os centros de mediação comunitária, não havendo qualquer restrição neste sentido ${ }^{7}$. Em geral, as demandas envolvem pessoas que se conhecem e que por vezes possuem relações continuadas repletas de sentimentos, o que pode dificultar o diálogo direto e a própria negociação entre elas (SALES, 2016, p. 486). Daí a importância do papel do terceiro facilitador enquanto agente propulsor de transformações sociais.

$\mathrm{Na}$ esfera comunitária, para atuar como mediador não é necessário ter ensino superior ou uma certificação específica. Esses colaboradores têm geralmente um amplo engajamento na localidade e têm um perfil condizente à prestação desse tipo de serviço. Devem ser pacientes, humildes, prudentes, criativos, imparciais, hábeis e perseverantes. No caso da cidade do Rio de Janeiro, por exemplo, o Tribunal de Justiça do Estado está capacitando ${ }^{8}$ alguns voluntários para trabalharem em paróquias e em dois espaços montados pela Prefeitura, um no Morro da Coroa e outro na Rocinha9.

No caso brasileiro, ainda que a maioria dos estados já contem com sua defensoria pública estruturada, há critérios econômicos ${ }^{7}$ que exigem comprovação de renda para o atendimento.

É verdade que o conceito de hipossuficiente passou por um forte alargamento. $\mathrm{O}$ critério de atuação da Defensoria Pública não se limita ao aspecto econômico, de modo que a Instituição pode prestar orientação jurídica a todos os indivíduos que estejam em situação de hipossuficiência organizacional, ou seja, desde que a pessoa esteja inserida em determinado grupo social vulnerável e com pretensão diretamente associada a essa situação de vulnerabilidade. Assim, poderão constituir causas de vulnerabilidade, entre outras, a idade, a incapacidade, a pertença a comunidades indígenas ou a minorias, a vitimização, a migração e o deslocamento interno, a pobreza, o gênero e a privação de liberdade.

Mas critérios econômicos ainda estão presentes para basilar a atuação da defensoria: Quanto ao critério econômico, consideram-se vulneráveis todas as pessoas que comprovarem renda familiar mensal igual ou inferior a três salários mínimos nacionais, considerando-se os ganhos totais brutos da sua entidade familiar. Na aferição da renda familiar, para fins de atendimento, deverão ser deduzidos: meio salário mínimo por dependente; parcelas devidas por lei ou determinação judicial, tais como impostos incidentes sobre a renda, verbas previdenciárias e pensão alimentícia; gastos ordinários com a moradia familiar, tais como despesas relativas ao consumo de água e energia elétrica, condomínio, aluguel e financiamento imobiliário para a aquisição de bem de família, até o limite de um salário mínimo nacional.

$8 \mathrm{O}$ curso de formação oferecido pelo Tribunal de Justiça do Rio de Janeiro tem duas fases: uma teórica, composta de $60 \mathrm{~h}$ de aulas presenciais dadas por instrutores do próprio tribunal; e uma outra posterior de $40 \mathrm{~h}$, sendo $30 \mathrm{~h}$ práticas e $10 \mathrm{~h}$ referentes à elaboração da rede e divulgação do núcleo. Até março de 2017, o curso está na sua etapa prática. Ao final dela, os mediadores finalmente estarão habilitados a atuar certificados pelo TJRJ.

9 Os centros da Prefeitura já estão na parte prática, em funcionamento. Já os que funcionarão em paróquias estão para iniciar esta fase de implementação (março de 2017). 


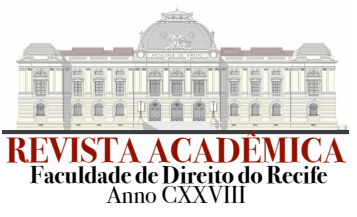

Não obstante o preparo e instrução sejam muito importantes, é preciso apontar que não há qualquer imposição legal nesse sentido. Dessa forma, é possível, por exemplo, que um condomínio crie seu próprio centro de mediação para resolver questões internas e opte por profissionais não tenham qualquer formação ou experiência na área (podem ser inclusive os próprios condôminos).

O procedimento é marcado pela informalidade e oralidade. Como a forma como que os participantes se expressam tende a refletir suas emoções, é preciso que o terceiro que medeia esteja atento à acolhida, desde que seja mantido o devido respeito ${ }^{10}$. Não há uma estrutura procedimental prescrita, o que abre espaço para que o procedimento se desenvolva conforme as circunstancias exigirem. Segundo orientação dos supervisores do Tribunal durante a etapa de formação teórica, é recomendável seguir as seguintes fases: 1. Reunião entre mediadores e observadores ${ }^{11} ; 2$. Recepção dos mediandos e dos $\operatorname{advogados}^{12} ; 3$. discurso de abertura e sessão conjunta inicial 13; 4. Primeira fala dos mediados e exposição do

10 Não é admitida qualquer forma de ofensa, grosserias, discriminações e outras reações do gênero. Essa compreensão de que a necessidade de estabelecer um convívio civilizado com o outro seja levada adiante é uma importante efeito gerado por esses procedimentos.

11 Antes que as partes cheguem ao local e depois do contato com o centro de mediação. É necessário uma reunião prévia para combinar a forma como vai se dar o procedimento. É preciso expor a maneira como se costuma trabalhar ao comediador. É muito importante esse planejamento da sessão da mediação.

12 É fundamental acolher as partes ao mesmo tempo em que é preciso ser assertivo.

13 Apresentação: Nome dos participantes e como gostariam de ser chamados; Explicação da proposta da mediação;Explicação do papel do mediador e suas características; Explicação das principais regras em relação aos mediandos (ex. proibição de xingamentos, palavras de baixo calão, agressividade, sem interrupções);

Ordem da discussão;Imparcialidade; Confidencialidade e suas exceções;

Construção de um acordo escrito com eficácia jurídica; Informações sobre o tempo do procedimento; Esclarecimento sobre reuniões individuais; Oportunidade de perguntas;

Papel dos advogados no processo. Durante a SESSÃO CONJUNTA INICIAL o Mediador tem os seguintes objetivos: 1. Estabelecer o rapport com os participantes (confiança):O rapport se refere ao grau de liberdade experimentado na comunicação, o nível de conforto das partes, o grau de precisão naquilo que é comunicado e qualidade de contato humano. Os mediadores frequentemente falam sobre a necessidade de desenvolver uma forma de ligação com os participantes. Sensação de confiança que deve ser passada as pessoas no primeiro contato com o mediador; Para isso, alguns pontos devem ser observados: Utilizar um tom de voz eficiente, de maneira calma e tranquila; Estar atento a comunicação não verbal: atento a seu comportamento, gestos e atitudes; Seu modo de se comunicar, seu semblante, humor; Não deixar transparecer preocupações pessoais; Não fixar o olhar em nenhum dos mediandos apenas; Evitar gestos bruscos e hostis;

2. Construir credibilidade pessoal $=$ ser leve e assertivo

3. Ajudar os mediandos a se sentirem ouvidos = escuta ativa, prestando atenção em ambos. Isso é muito importante porque as partes vão reproduzir o comportamento do mediador nesse sentido. A postura do mediador é o espelho do mediando e precisa garantir que os mediandos sintam-se ouvidos.

4. Instruir os participantes sobre o processo de mediação; 5. Conseguir o compromisso de mediar;

6. Identificar o tom do caso / Ambiente emocional;

7. Dar aos mediandos oportunidade de ouvir o outro. 


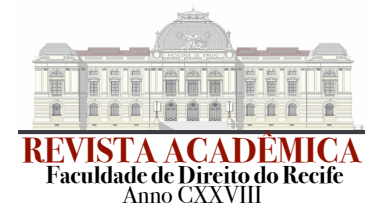

motivo do interesse pela mediação; 5. elaboração do resumo e da pauta do mediador; 6 . Decidir sobre a necessidade de sessões privadas e se for o caso, iniciar com a parte que procurou o centro; 7. Projetar estratégias partindo das habilidades próprias da mediação para o restabelecimento da comunicação, abrindo o caminho para a formulação de soluções plausíveis; 8. Redação do termo final, com ou sem acordo.

\section{EMPODERAMENTO, CIDADANIA E DEMOCRACIA}

O empoderamento é o processo de fortalecimento dos sujeitos nos espaços de participação social e democratização política. Compreende o resgate da individualidade para que possa se enxergar, compreender o outro, e a partir da ampliação de algumas perspectivas intrínsecas, tentam solucionar os pontos de divergência.

Diz respeito à autodeterminação das pessoas, que abrange três conteúdos: o aprendizado individual e local, que se refere ao conhecimento sobre responsabilidades inclusive sobre situações futuras; o aprimoramento das habilidades pessoais e comunicativas, que abre a possibilidade de enfrentar questões individuais coletivamente e refletir sobre os impactos de suas atitudes na vida do outro; e a capacidade de pensar em alternativas para superar as próprias contendas, que representa a saída definitiva do isolamento do indivíduo no sentido de averiguar o que está ao seu alcance para solucionar a divergência (FOLEY, 2016, p. 516).

De acordo com a doutrina estadunidense ${ }^{14}$, o empoderamento na mediação refere-se à atividade do mediador de fazer com que os mediandos compreendam mutuamente seus

14 Nas décadas de 1960 e 1970, conforme aponta Rodrigo Horochovski (2006, p.3), localizam-se as primeiras referências de apropriação, pelos movimentos civis nos Estados Unidos da América, do termo empoderamento (empowerment). Os grupos civis organizados na luta por seus direitos apropriam-se do tema, enxergando, no empoderamento, a essência da luta e conquista de direitos. Pode-se citar, como exemplo, as lutas dos movimentos Black Power e feminista. Todos estes grupos moveram-se e se movem pela tomada de consciência da condição de oprimidos e pela compreensão da necessidade de união e fortalecimento dos seus integrantes para a luta, fazendo, o empoderamento, parte das suas reflexões e estratégias de atuação. 


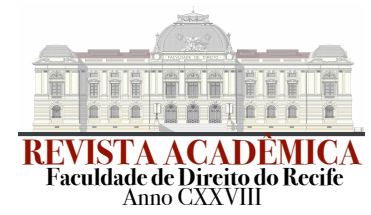

interesses e necessidades. Somado a isso, esse empowerment 15 também diz respeito ao papel do condutor do procedimento de desenvolver as capacidades e qualidades dos mediados para gerirem e elaborarem a solução autocompositiva e consensual do conflito (AZEVEDO, 2010, p. 141).

Kleba e Wendausen (2009) trazem a divisão do empoderamento em três dimensões: 1. psicológica ${ }^{16}$, que diz respeito à mudança de mentalidade com a percepção pelo sujeito das próprias forças resultando em um comportamento de autoconfiança; 2. a grupal, representada pelo fortalecimento das organizações, que pode ser fomentado por meio de compartilhamento de papéis de liderança, de decisões, amplificação e nitidez nas diferentes formas de comunicação, dentre outras ${ }^{17} ; 3$. e a política ${ }^{18}$, correspondente a uma redistribuição de poderes políticos e de decisões na sociedade, efetivando a democracia.

Do ponto de vista social, a mediação comunitária é um importante instrumento de transformação cidadã. Por meio dela há a construção de uma educação de paz enquanto uma alternativa à litigiosidade. E a partir do contexto comunitário, isto implica um aprimoramento

\footnotetext{
$15 \mathrm{O}$ empoderamento apresenta ainda outras dimensões, podendo ter o propósito de capacitar os sujeitos para uma compreensão ampliada de direitos, dando-lhes condições jurídicas para acesso à justiça. A promoção do empoderamento por meio da mediação, para além de auxiliar os mediandos a solucionarem seus conflitos de forma consciente, pode ajudá-los a conhecer direitos, especialmente no que concerne aos direitos humanosfundamentais e os caminhos para efetivá-los, fomentando o acesso à justiça em sentido amplo. Para que haja o empoderamento dos envolvidos no processo de mediação em relação a esses direitos humanos-fundamentais se faz necessário o acesso à informação e ao conhecimento, pois é preciso conhecer os meios de se obter o acesso à justiça. No contexto brasileiro, parcela da população sofre com as limitações de acesso à informação, não sabendo a melhor forma de se solucionar uma demanda, de acessar um serviço público ou mesmo como decidir conscientemente sobre suas questões, justamente por não ter conhecimento e informações suficientes. Deste modo, grade parte dos mediandos chega à mediação sem o empoderamento necessário para compreender sua situação conflituosa de maneira a completa e os direitos que a tangeciam, o que pode ser fomentado pela atuação do mediador (ORSINI; SILVA; 2013, p. 12).
}

$16 \mathrm{O}$ processo de empoderamento seria o conjunto de ações, movimentos, diálogos capazes de proporcionar a percepção, pelo sujeito, acerca de suas forças e os resultados seriam a mudança de mentalidade ao passar a confiar em si mesmo, a ter autoconfiança. Ressalta-se que, em que pese tratar-se do empoderamento individual, ele não ocorre sem a interação do individuo com outro, depende do conflito, do diálogo - mediado, no caso - e das reflexões conjuntas (Ibid, p. 738).

17 Por meio destas, os resultados de empoderamento esperados são a crença nos membros da organização grupal, de forma a possibilitar o compartilhamento de lideranças; a oportunidade de exercício de múltiplos papeis sociais; e a consequente promoção do crescimento e confiança. Assim, a organização empoderada é capaz de trabalhar em rede, e, na busca pelo atingimento de suas metas - de acordo com os interesses que adota influencia políticas e desenvolve formas para aumentar a efetividade de suas lutas. (KLEBA; WENDAUSEN, 2009, p. 740)

$18 \mathrm{O}$ processo de empoderamento conta com a criação de um ambiente propício ao desenvolvimento do sentimento de pertencimento à comunidade; de consciência, do individuo, acerca dos interesses e objetivos conjuntos, assim como da disposição possível dos recursos e informações. Um ambiente no qual haja valorização da participação de cada indivíduo (Ibid, p. 741). 


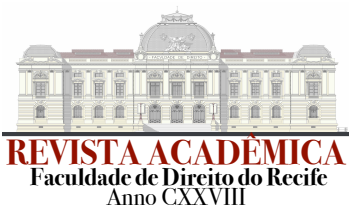

do exercício de direitos, com a reconquista de valores fundamentais como o respeito pelos direitos humanos, garantia da igualdade entre mulheres e homens, participação democrática, e a compreensão, tolerância e solidariedade ${ }^{19}$ entre os indivíduos da localidade, por vezes, completamente afastados desses princípios.

Isso é possível, uma vez que as pessoas são orientadas pelo mediador a se portarem de maneira respeitosa e harmoniosa com o próximo, não se admitindo qualquer forma de ofensa, grosserias, discriminações e outras reações do gênero. Essa compreensão de que a necessidade de estabelecer um convívio civilizado com o outro precisa ser levada adiante é uma importante contribuição do procedimento.

Parece indiscutível frente a tantos benefícios que à medida que a conscientização e divulgação forem feitas, a busca natural para sanar determinados problemas será pelos centros de mediação ${ }^{20}$. Os comunitários, justamente mais conectados com a realidade da região e com mediadores inseridos na comunidade, se apresentam como a alternativa mais legítima ${ }^{21} \mathrm{e}$ imediata. Cabe enfatizar que não há justiça sem plena cidadania e esta precisa começar a ser pensada, primeiramente, em uma perspectiva localizada.

Impõe destacar ainda que todos os serviços prestados pelos centros comunitários são gratuitos. Na realidade do Rio de Janeiro, que será abordada de forma minuciosa mais adiante, os mediadores capacitados foram instruídos não só para a realização do procedimento de mediação em si mas também para dar o encaminhamento e a orientação ${ }^{22}$ devidas. Desse

${ }^{19}$ É o que liga os indivíduos diretamente à sociedade, bem como o conjunto de sentimentos e crenças em comum entre as pessoas que integram um grupo (CARNEIRO, 2016).

${ }^{20}$ Estatisticamente, é possível ter uma ideia do impacto que essa mudança poderá representar com a análise dos temas mais frequentes que chegam aos Tribunais e que são todos matérias passíveis de mediação, como por exemplo, rescisão de contrato de trabalho, contratos civis, responsabilidade civil e de fornecedor, indenização por dano moral e alimentos; que totalizam mais de $27 \%$ dos casos.

$21 \mathrm{O}$ âmbito comunitário é, em si, um espaço de grande riqueza por sua aptidão em difundir e aplicar os métodos pacíficos de gestão de conflitos ou tramitação das diferenças. A mediação, comi instrumento apto a este propósito, brinda os protagonistas - aqueles que compartilham o espaço comunitário - a oportunidade de exercer uma ação coletiva na qual eles mesmos são os que facilitam a solução dos problemas que se apresentam em suas pequenas comunidades. Neste sentido, o desenvolvimento desses processos assim como a transferência de ferramentas e técnicas específicas de mediação aos integrantes das comunidades, constituem um valioso aporte e um avanço concreto relativo à nossa maturidade como sociedade e colabora efetivamente em prol de um ideal de uma vida comunitária mas satisfatória (NATÓ, 2006, p. 109).

22 Importante destacar que não se trata aqui de uma orientação jurídica mas tão somente quanto ao órgão público ao qual cabe tratar de determinada questão (ex. se for um caso envolvendo consumidor, direcionar qual o Procon mais próximo; ou em se tratando de um crime, e portanto não sendo mediável, orientar à delegacia responsável, etc). 


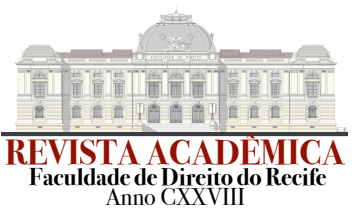

modo, visa a permitir, portanto, não só o conhecimento sobre aparato estatal e de outros serviços oferecidos pelo Poder Público ou pela Igreja Católica, como também conectam ${ }^{23}$ as pessoas à essas esferas. E tudo isso completamente isento de custos.

Cada centro é responsável pela elaboração do que se convencionou chamar de "rede", ou seja, o mapeamento dos serviços prestados na região24, bem como os locais onde são prestados. É tarefa dos mediadores visitar esses espaços, divulgar o trabalho realizado nos núcleos de mediação e fazer contato com os responsáveis. Isso garante que o direcionamento do mediando seja feito de forma direta e efetiva.

Os instrumentos formais de participação democrática como o voto e os plebiscitos e referendos não se mostram mais suficientes para atender às demandas de uma população consultada esporadicamente ${ }^{25}$ sobre certas matérias. É preciso que os cidadãos a exerçam cotidianamente como forma de vida (THESING, 2005, p. 145). A medição é um processo democrático 26 que rompe/dissolve os marcos dos conflitos, acolhendo a desordem e buscando a sua resolução pelo diálogo e compreensão entre as partes no intuito de garantir a democracia e a cidadania (SPENGLER, 2008).

\footnotetext{
${ }^{23}$ Como já foi dito, os centros comunitários contam com a elaboração de uma rede. É feito um mapeamento dos principais serviços (sobretudo públicos) oferecidos próxima à localidade do centro, bem como é criado uma interação com cada um deles. A divulgação do funcionamento dos centros comunitários se dá, em grande medida, a partir desses contatos que estão sendo criados.
}

24 Por exemplo, órgão de defesa do consumidor, detran, delegacia da área, Juizado de Pequenas Causas, sindicatos, hospitais, dentre outros.

$25 \mathrm{O}$ voto para cada mandato Legislativo ou Executivo só é exercido a cada quatro anos. E são raros os casos em o Legislativo abre à consulta pública por meio de plebiscito ou referendo. Em toda a sua História, o Brasil realizou 4 plebiscitos e 2 referendos. Foram eles: Em 1963 sobre o sistema de governo, durante a gestão de João Goulart. O país havia adotado o parlamentarismo pouco depois que Jango assumira a presidência, em 7 de setembro de 1961, mas a maioria dos eleitores preferiu retornar ao sistema presidencialista. Em 1993, sobre o regime e o sistema de governo no Brasil (monarquia parlamentar ou república; parlamentarismo ou presidencialismo). Na ocasião, a maior parte do povo brasileiro optou por manter o regime republicano e o sistema presidencialista. Em 23 de outubro de 2005 foi realizado um referendo sobre a proibição da comercialização de armas de fogo e munições, com vistas à aprovação ou não do disposto no art. 35 da Lei $n^{\circ}$ 10.826, de 23 de dezembro de 2003, conhecida como Estatuto do desarmamento. Nesta consulta, a maioria do eleitorado preferiu votar pelo "não", isto é, contra a proibição. Em 11 de dezembro de 2011, foi realizado um plebiscito, somente no estado do Pará, sobre a aprovação ou não da divisão do estado em três, sendo eles: o próprio Pará, Carajás e Tapajós. A população votou contra a criação dos dois novos estados. E, por fim, em 2014, o plebiscito sobre a criação de dois distritos em Campinas.

Para maiores consultas sobre plebiscitos e referendos: < http:/www.tse.jus.br/eleicoes/plebiscitos-e-referendos/ plebiscito-e-referendo> acesso em 3 de mar 2017.

26 A mediação pode ser vista como a melhor forma de realização da autonomia, da cidadania, da democracia e dos direitos humanos, constituindo as práticas sociais de mediação em um mecanismo de exercício da cidadania, na medida em que educam e auxiliam as partes envolvidas no conflito a tomarem decisões, sem a interferência de terceiros que deliberem por elas (COLARES, 2005, p.101). 


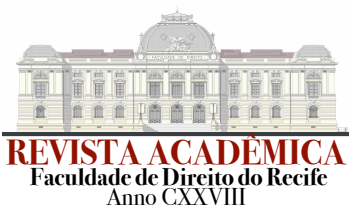

A mediação comunitária incrementa a prática democrática 27 , na medida em que incentiva a participação ativa dos indivíduos, os quais passam a deter amplo e efetivo poder de melhorar a própria realidade e o ambiente no qual estão inseridos. Possibilita uma interação entre as pessoas e provoca mudanças positivas entre elas (SALES, 2016, p. 497). É realizada na comunidade28, para a comunidade e pela comunidade, promovendo a sua emancipação ao cuidar do desenvolvimento de mecanismos voltados à sua autodeterminação, coesão social ${ }^{29}$ e solidariedade. $\mathrm{O}$ acordo é encarado tão somente como uma consequência de uma interlocução consistente e consciente.

Caroline Wust (2014, p. 92) observa que a mediação comunitária é um meio eficaz não apenas por proporcionar a democratização do acesso à justiça, mas por empoderar os sujeitos e torná-los verdadeiros cidadãos. Cleber Francisco Alves (ob. cit., p. 337) ressalta a importância da sociedade civil se mobilizar no sentido de contribuir para o alcance objetivo da igualdade no acesso à justiça para todos.

\section{A MEDIAÇÃO COMUNITÁRIA A PARTIR DO CONVÊNIO COM O TJRJ}

27 O principal aspecto da análise atual de democracia consiste, portanto, no avanço do "fator democrático". Isso porque a noção paulatinamente vem sendo ampliada até atingir os diferentes âmbitos de atuação do ser humano (trabalho, economia, educação etc).

28 O termo "comunidade" está sendo usado neste trabalho como sinônimo de localidade, que não significa necessariamente, áreas carentes. No Rio de Janeiro, por exemplo, o TJRJ está formando mediadores comunitários para atuarem em Ipanema e barra da tijuca, bairros com elevado poder aquisitivo.

Mas reconhecemos que frequentemente, alguns autores empregam o termo para se referirem especificamente à essas áreas mais pobres. Nesse sentido: A mediação nas comunidades traduz o exercício de cidadania e de democracia, pois permite que os cidadãos, até então socialmente excluidos, resolvam por si mesmos seus conflitos com o auxílio de um mediador. Os mediadores comunitários, auxiliam na solução das controvérsias existentes dentro da própria comunidade, o que, por consequência, possibilita a inclusão, a participação e a responsabilização do cidadão por suas escolhas. Os mediadores são os próprios membros da comunidade, capacitados a realizar a mediação, dedicando parte do seu tempo, de forma gratuita, para resolver os interesses da comunidade, trazendo a esses mediados conhecimentos, valores e comportamentos de fortaleçam uma cultura de paz e em beneficio de todos os envolvidos (TRENTIN; COITINHO; CASAGRANDE, 2014, p. 9).

29 Em substituição a tradição visão adversarial ganhador-perdedor, enfatiza-se a relação entre os valores e práticas voltados à realização da democracia e da convivência pacifica, contribuindo para a construção de um consenso entre os indivíduos, no qual o respeito e a tolerância são os aspectos característicos para proeminentes (coesão social). Há um caminho para o exercício da cidadania participativa consistente na busca conjunta, consciente e amadurecida das partes envolvidas em prol do tratamento do conflito existente. 


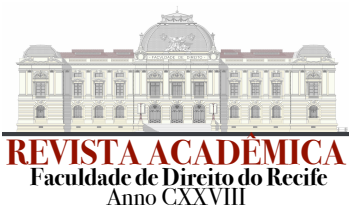

Conforme já foi mencionado, qualquer local pode oferecer serviços de mediação extrajudicial independente de formação específica dos mediadores. Assim, associações, organizações, condomínios podem ter centros comunitários com voluntários que se disponham a fazer com que as partes dialoguem sobre suas questões.

Mas o objetivo deste trabalho é tratar sobre os núcleos formados a partir da iniciativa do Tribunal de Justiça do Rio de Janeiro. Em 2015, este órgão firmou dois convênios: um com a prefeitura da cidade e outro com a arquidiocese metropolitana. A escolha dessas instituições foi devido ao fato de contarem com estruturas consolidadas e espaço disponível.

Assim, no ano de 2016 foram inaugurados dois centros com a Prefeitura, um no Catumbi, denominado de Paulo César Salomão ${ }^{30}$ e outro na Rocinha ${ }^{31}$, que recebeu o nome de Salim Salomão. Na parte relacionada à Igreja ${ }^{32}$, foram abertos em sete paróquias ${ }^{33}$, em seis dos oito Vicariatos que compõe a arquidiocese.

O TJRJ programou um curso de formação para mediadores comunitários em duas fases: a primeira parte teórica composta de 60 horas seguida da prática de 40 horas. Destas últimas, 10 horas relativas à elaboração da rede e 30 horas de acompanhamento de procedimentos de mediação conduzidos por supervisores do Tribunal. Até o momento (janeiro de 2018), os centros da prefeitura concluíram a segunda etapa. Já os localizados em Igrejas estão com esta fase em andamento. A previsão é que a cerimônia de conclusão do curso aconteça ainda este ano.

Os mediadores foram escolhidos em decorrência do seu engajamento na comunidade. É um trabalho voluntário em que, portanto, não há contraprestação salarial. Os atendimentos são realizados preferencialmente em duplas de colaboradores de acordo com a disponibilidade. Cada centro conta com pelo menos um (1) mediador adjunto que é

\footnotetext{
${ }^{30}$ Notícia sobre a inauguração: <http://agenciabrasil.ebc.com.br/geral/noticia/2015-12/prefeitura-do-rioinaugura-primeiro-centro-de-mediacao-comunitaria> acesso em 7 de mar de 2017.

31 Notícia sobre a inauguração: <http://prefeitura.rio/web/guest/exibeconteudo?id=5980741> acesso em 7 de mar de 2017.

${ }^{32}$ Notícia sobre a abertura do centro comunitário na Arquidiocese: <http://arqrio.org/noticias/detalhes/5222/ mediacao-nas-paroquias-da-zona-sul> acesso em 7 de mar de 2017.

33 Paróquia Santa Luzia e Paróquia São Francisco de Paula no Vicariato Jacarepaguá; Paróquia Nossa Senhora da Conceição no Vicariato Santa Cruz; Paróquia Nossa Senhora de Fátima no Vicariato norte; Paróquia Nossa Senhora da Paz no Vicariato Sul; Vicariato Leopoldina; e Catedral no Vicariato urbano.
} 


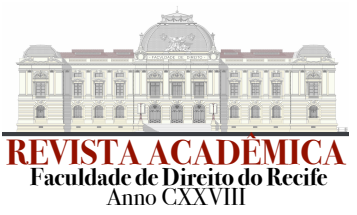

responsável por coordenar e organizar as atividades e horários.

Todo mês deverá ser enviado ao Tribunal uma planilha com os procedimentos realizados, o tipo de conflito, mediadores que atuaram, número de sessões feitas e se foi firmado acordo ou não. Esses dados serão transformados em estatísticas que permitirão acompanhar como o trabalho que vem sendo desenvolvido tanto pelo TJRJ quanto pelo Conselho Nacional de Justiça, o CNJ.

O Núcleo Permanente de Métodos Consensuais de Solução de Conflitos NUPEMEC, promove reuniões com representantes de todos os centros a cada 2 meses para colher informações sobre o andamento da formação dos mediadores e sobre as mediações que vêm sendo realizadas. $\mathrm{O}$ grande entrave levantado pela quase totalidade dos Vicariatos ${ }^{34}$ foi a baixa procura, a ponto de ainda ser insuficiente para completar a carga horária mínima necessária. Feita essa constatação, chegou-se à conclusão de que era fundamental a intensificação da divulgação dos serviços de mediação prestados pelos núcleos nas próprias paróquias em que são inseridos como também nas demais Igrejas que compõe o mesmo Vicariato.

Até agora, com a última reunião realizada em dezembro de 2017, a falta de demanda continua sendo a maior dificuldade relatada pelos participantes do projeto. Os voluntários dos centros da Coroa e da Rocinha, não obstante, não enfrentam mais esse dilema, graças à intensa campanha realizada, que também incluiu as redes sociais, participação em eventos da comunidade e em eventos de capacitação externos.

Segundo relatos desses colegas, o contato com empresas que atuam nas localidades através de email foi fundamental para ampliar o conhecimento sobre o funcionamento dos centros. Por meio dessa interação construída, algumas reclamações de moradores relacionadas a OI telefonia, por exemplo, são solucionadas através de um simples telefonema. Corroborando a importância de comunicação com o empresariado local, o centro da Catedral,

\footnotetext{
34 Foi verificado que os centros ligados à Prefeitura já atingiram as horas práticas suficientes ao término da formação. E compartilharam a experiência da ampla divulgação realizada dentro da comunidade.

Quanto aos núcleos paroquiais, seus coordenadores se manifestaram no sentido da baixa procura pelos centros e sugeriram que a parte prática fosse realizada junto aos CEJUSC (centro judiciário de solução de conflitos e cidadania). O TJRJ encarou com ressalvas essa possibilidade, sendo a principal motivo o perigo de "contaminação" da mediação comunitária por práticas correntes na mediação judicial.

O centro de mediação Nossa Senhora da Paz está em andamento na fase prática da capacitação de seus mediadores mas ainda não teve nenhum procedimento realizado até dezembro de 2017.
} 


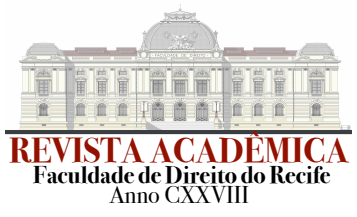

que engloba o vicariato urbano, contou que estava iniciando uma mediação com a empresa responsável por gerir o VLT do Rio.

O núcleo Nossa Senhora da $\mathrm{Paz}^{35}$, que abrange toda a zona sul da cidade, também já participou de eventos para ampliar não só o conhecimento sobre a existência do centro, como também para esclarecer e tirar dúvidas sobre a proposta de resolução de conflitos pela via consensual. Estivemos nos dois momentos do "Abraço da Paz - Paz de A a Z"; o primeiro realizado na Praça Nossa Senhora da Paz, e o segundo em frente à Igreja São José da Lagoa. Em ambos levamos banners e material para distribuição aos interessados. Assim como sugerido, estamos agendando visitas a órgãos inseridos na proximidade, como o Poupa tempo, hospitais e a estabelecimentos comerciais. Com isso, esperamos aproximar as pessoas e aumentar nossa atuação; mas somos conscientes de que tal mudança cultural exige tempo e será um longo caminho até conseguirmos diminuir a mentalidade litigante de nossa sociedade.

\section{CONCLUSÃO}

A mediação comunitária na cidade do Rio janeiro que vem sendo implementada a partir da supervisão do Tribunal de Justiça está sendo desenvolvida em espaços cedidos pela Prefeitura e por paróquias de seis vicariatos. O apoio do Judiciário se dá na formação dos mediadores comunitários através de um curso teórico e prático que desenvolve habilidades de comunicação e negociação. O objetivo é desafogar dos juízes questões simples e que poderiam ser solucionadas pelas próprias partes: conflitos de vizinhança, entre lojistas, direito do consumidor, guarda de filhos, negociação de dívidas, dentre outros.

A maior dificuldade apontada até agora é sobretudo a carência de procura de interessados em realizar a mediação. Ainda há muito descrédito em relação ao procedimento. Durante as reuniões dos centros com o NUPEMEC foram sugeridas algumas medidas como a intensificação do trabalho de divulgação junto à comunidade e em locais como hospitais, órgãos públicos e estabelecimentos; organização de eventos para promover a mediação e suas

35 Para realizar procedimentos de Mediação no núcleo Nossa Senhora da Paz, basta deixar o contato na Secretaria da paróquia no endereço: Rua Visconde de Pirajá, 339 - Ipanema (edifício ao lado da Igreja, em frente à Praça Nossa Senhora da Paz). 


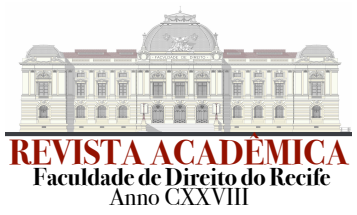

vantagens; e participação em congressos e encontros para aprimorar a capacitação e trocar experiências.

Não obstante esses entraves, uma vez sendo superados há uma enorme perspectiva de melhora das relações na localidade, um aperfeiçoamento do exercício dos direitos e uma consequente diminuição do número de ações ajuizadas. Ainda que em um primeiro momento os impactos em termos estatísticos possam ser pouco expressivos, a mudança da cultura da litigância tende a repercutir positivamente sobre o empoderamento do cidadão.

\section{REFERÊNCIAS}

ALMEIDA, Diogo A. Rezende de; PANTOJA, Fernanda Medina. Áreas de atuação da mediação de conflitos. In: ALMEIDA, Tania; PELAJO, Samantha; JONATHAN, Eva. Mediação de conflitos para iniciantes, praticantes e docentes. Salvador: Ed. Juspodium, 2016.

ALVES, Cleber Francisco. Justiça para todos! Assistência Jurídica gratuita nos Estados Unidos, na França e no Brasil. Rio de Janeiro: Editora Lumen Juris, 2006.

AZEVEDO, André Gomma (org.). Manual de Mediação Judicial. Brasília/DF: Ministério da Justiça e Programa das Nações Unidas para o desenvolvimento - PNUD, 2009.

CAPPELLETTI, Mauro; GARTH, Bryant. O acesso à justiça. Porto Alegre: Sergio Antonio Fabris editor, 1988.

CARNEIRO, Maria Francisca. Mediação como renovação do conceito de justiça. Revista Jus navigandi, Teresina, ano 19, n. 3968, 13 maio 2014. Disponível em: <http://jus.com.br/ $\operatorname{artigos} / 28391>$.

FOLEY, Glaucia Falssarella. Justiça comunitária: uma experiência emancipatória. In: ALMEIDA, Tania; PELAJO, Samantha; JONATHAN, Eva. Mediação de conflitos para iniciantes, praticantes e docentes. Salvador: Ed. Juspodium, 2016.

KLEBA, Maria Elisabeth; WENDAUSEN, Agueda. Empoderamento: processo de fortalecimento dos sujeitos nos espaços de participação social e democratização política. Saúde e Sociedade,. São Paulo, v.18, n.4, p. 733-743, 2009. 


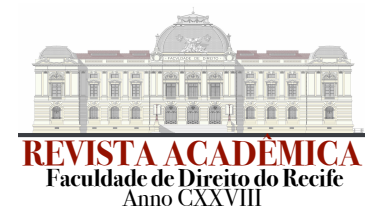

MERRY, Sally Eagle. Albie Davies: La mediación comunitária como organización de la comunidad. In: KOLB, Deborah M. Y Asociados. Quando hablar da resultado: Perfis de mediadores. Buenos Aires, Barcelona, México: Paidós, 1996.

NATÓ, Alejandro Marcelo; QUEREJAZU, Maria Gabriela Rodriguez; CARBAJAL, Liliana Maria. Mediación Comunitária. Conflitos en el Escenario Social Urbano. Buenos Aires: Editorial Universidad, 2006.

ORSINI, Adriana Goulart de Sena; SILVA; Nathane Fernandes. Mediação para a democracia: cidadania, participação e empoderamento no âmbito da resolução de conflitos. 2013.

Disponível em <http://www.publicadireito.com.br/artigos/?cod=3006a068501fbf78> acesso em 6 de mar 2017.

SALES, Lilia Maia de Morais. Mediação comunitária, Escola Transformativa e Democracia. In: ALMEIDA, Tania; PELAJO, Samantha; JONATHAN, Eva. Mediação de conflitos para iniciantes, praticantes e docentes. Salvador: Ed. Juspodium, 2016.

SPENGLER, Fabiana Marion. Tempo, Direito e Constituição: reflexos na prestação jurisdicional do Estado. Porto Alegre: Livraria do Advogado, 2008.

THESING, Josef. La democracia: también una forma de vida. Diálogo Político: Buenos Aires, v. 22, n.1, p. 141-155, 2005.

TRENTIN, Taise Rabelo Dutra; COITINHO, Viviane Teixeira Dotto; CASAGRANDE, Aline. Mediação Comunitária como Política Pública de Inclusão Social no tratamento de conflitos. 2014. Trabalho apresentado no $11^{\circ}$ Seminário Internacional de demandas sociais e políticas públicas na sociedade contemporânea, Santa Catarina, 2014. Disponível em $<$ https:// online.unisc.br/acadnet/anais/index.php/sidspp/article/viewFile/11803/1537> acesso em 7 de mar. 2017.

WUST, Caroline. Mediação comunitária e acesso à justiça: as duas faces da metamorfose social. Santa Cruz do Sul: Essere Nel Mondo, 2014.

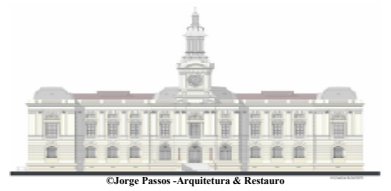

